\title{
Quality characteristics of semi-dried restructured jerky: combined effects of duck skin gelatin and carrageenan
}

\author{
Se-Myung Kim ${ }^{1}$, Tae-Kyung Kim ${ }^{1}$, Su-Kyung Ku${ }^{1}$, Min Jung Kim², \\ Samooel Jung ${ }^{3}$, Hae In Yong ${ }^{1 *}$ and Yun-Sang Choi ${ }^{1 *}$ \\ ${ }^{1}$ Research Group of Food Processing, Korea Food Research Institute, Wanju 55365, Korea \\ ${ }^{2}$ Research Group of Natural Materials and Metabolism, Korea Food Research Institute, Wanju 55365, Korea \\ ${ }^{3}$ Division of Animal and Dairy Science, Chungnam National University, Daejeon 34134, Korea
}

Received: Mar 19, 2020

Revised: May 3, 2020

Accepted: May 15, 2020

*Corresponding author

Yun-Sang Choi

Research Group of Food Processing,

Korean Food Research Institute,

Wanju 55365, Korea.

Tel: +82-63-219-9387

E-mail: kcys0517@kfri.re.kr

Hae In Yong

Research Group of Food Processing

Korean Food Research Institute,

Wanju 55365, Korea.

Tel: +82-63-219-9461

E-mail: awsm_y@kfri.re.kr

Copyright $\odot 2020$ Korean Society of Animal Sciences and Technology.

This is an Open Access article distributed under the terms of the Creative Commons Attribution Non-Commercial License (http:// creativecommons.org/licenses/by$\mathrm{nc} / 4.0 /$ ) which permits unrestricted non-commercial use, distribution, and reproduction in any medium, provided the original work is properly cited.

ORCID

Se-Myung Kim

https://orcid.org/0000-0003-2250-7243

Tae-Kyung Kim

https://orcid.org/0000-0002-6349-4314

Su-Kyung Ku

https://orcid.org/0000-0002-9158-8254

Min-Jung Kim

https://orcid.org/0000-0003-0205-016X

Samooel Jung

https://orcid.org/0000-0002-8116-188X

Hae In Yong

https://orcid.org/0000-0003-0970-4496

\section{Abstract}

The present study investigated the effects of duck skin gelatin and carrageenan on the quality of semi-dried restructured jerky. Restructured jerky was prepared as follows: G0 (control, without duck skin gelatin and carrageenan), G0C (0.3\% carrageenan), G0.5 (0.5\% duck skin gelatin), G0.5C (0.5\% duck skin gelatin and $0.3 \%$ carrageenan), G1 (1.0\% duck skin gelatin), and G1C ( $1.0 \%$ duck skin gelatin and $0.3 \%$ carrageenan). The moisture content was the highest for the semi-dried restructured jerky from $\mathrm{G} 0.5 \mathrm{C}$ and $\mathrm{G} 1 \mathrm{C}$ groups, which showed the lowest for shear force value $(p<0.05)$. The processing yield of semi-dried restructured jerky with carrageenan was higher compared to that of the control group $(p<0.05)$. The rehydration capacities of G0.5, G0.5C, and G1C groups were significantly higher than the rehydration capacity of the control group $(p<0.05)$. Water activity, lightness, yellowness, flavor score, texture score, and overall acceptability were the highest $(p<0.05)$ for the semi-dried restructured jerky from the G1C group. No significant $(p>0.05)$ difference was observed in appearance score among restructured jerky prepared from duck skin gelatin and carrageenan. Thus, the addition of $1.0 \%$ duck skin gelatin and $0.3 \%$ carrageenan to semi-dried restructured jerky formulations results in the optimization of quality characteristics.

Keywords: Semi-dried restructured jerky, Duck skin gelatin, Carrageenan, Shear force, Overall acceptability

\section{INTRODUCTION}

Jerky, consumed as a traditional and popular dried meat product, is prepared as whole-muscle jerky and restructured jerky [1]. In particular, restructured jerky is capable of mass production of standardized products during the manufacturing process [2]. Restructured jerky is economic and environmentally friendly, as it may be prepared using the unused parts of pork or those discarded during production [2]. However, restructured jerky has a tough texture from the drying process [3]. Studies conducted to address this problem have employed modified drying conditions (semi-dried condition) or added ingredients that enhance water holding capacity [4-7].

In restructured jerky, hydrocolloids are useful functional ingredients that improve tenderness [8]. 
Yun-Sang Choi

https://orcid.org/0000-0001-8060-6237

Competing interests

No potential conflict of interest relevant to

this article was reported.

Funding sources

This research was supported the High Valueadded Food Technology Development Program (2020-118011) by the Ministry of Agriculture, Food and Rural Affairs (Republic of Korea). This research was also partially supported by 2017 Ottogi Foundation research program.

Acknowledgements

Not applicable.

Availability of data and material Upon reasonable request, the datasets of this study can be available from the corresponding author.

\section{Authors' contributions}

Conceptualization: Yong HI, Choi YS.

Data curation: Kim SM, Ku SK.

Formal analysis: Kim SM.

Methodology: Kim SM, Kim TK.

Software: Kim MJ, Jung S.

Validation: Kim SM, Jung S.

Investigation: Yong $\mathrm{HI}$, Choi YS

Writing - original draft: Kim SM, Yong HI, Choi YS.

Writing - review \& editing: Kim SM, Yong HI, Choi YS.

Ethics approval and consent to participate This article does not require IRB/IACUC approval because there are no human and animal participants.
One of the most common hydrocolloid gums in the meat industry is carrageenan [9]. Carrageenan, a mucopolysaccharide obtained from red algae, is composed of D-galactose and 3,6-anhydro-D-galactose linked with a $\beta-1-4$ linkage or an $\alpha-1-3$ linkage [10]. In the preparation of meat products, carrageenan dissolved during thermal processing forms a gel upon cooling [11]. It enhances water retention, texture, and consistency of meat products when used in combination with gelatin and other ingredients [11,12]. Pietrasik and Li-Chan [13] indicated that carrageenan in meat batter improved the water holding capacity and the cooking loss of meat gels.

In food industries, Gelatin known as hydrocolloid has been used widely due to its unique functional properties [14]. Its gel formation ability is one of the most useful characteristics when preparing restructured meat products [15]. Gelatin is derived from the partial hydrolysis of collagen from cowhide or pigskin [8]. However, new alternative sources of gelatin are in demand owing to the outbreak of foot-and-mouth disease and bovine spongiform encephalopathy [14]. Poultry by-products, especially skin and feet, have abundant gelatin and may serve as a replacement for the existing gelatin sources [16]. Gelatin from chicken or duck feet has been studied and the physicochemical properties of restructured jerky containing that gelatin was improved $[14,17]$. However, little data is available on the effect of duck skin gelatin and its combination with carrageenan on restructured jerky.

In this direction, here we conduct this study to increase the value of discarded duck skin by extracting gelatin and determining its effects with or without carrageenan on the quality of semidried restructured jerky.

\section{MATERIALS AND METHODS}

\section{Preparation of duck skin gelatin}

Duck skin gelatin was prepared according to the method of Kim et al. [18] with some modifications. Duck skin (Pekin duck, Cherry Valley strain; purchased from Farm duck, Jeongeup, Korea) was soaked for five times in a solution that was adjusted $\mathrm{pH} 1$ to facilitate swelling. After incubation for $24 \mathrm{~h}$ at ambient temperature $\left(20 \pm 2^{\circ} \mathrm{C}\right)$, the swollen skin was washed in flowing tap water for $48 \mathrm{~h}$ at ambient temperature. Then, $1 \mathrm{~kg}$ of swollen skin was heated using a super-heated steamer (QF-5200C, Naomoto, Osaka, Japan; oven temperature: $150^{\circ} \mathrm{C}$, steam temperature: $150^{\circ} \mathrm{C}$ ). When duck skin was melted, it was filtered at a holding time of $12 \mathrm{~h}$ at $2{ }^{\circ} \mathrm{C}$ to separate fat and non-fat ingredients. Separated non-fat ingredients, called crude gelatin, were adjusted at $\mathrm{pH} 7$ with $0.1 \mathrm{~N}$ $\mathrm{NaOH}$ and dehydrated using a spray dryer (B-290, Buchi, New Castle, DE, USA). Drying conditions were as follows: inlet temperature of $120^{\circ} \mathrm{C}$, aspirator $100 \%$, pump $15 \%$. Duck skin gelatin had $0.47 \%$ moisture, $91.28 \%$ protein, $1.94 \%$ fat, and $6.32 \%$ ash. The color of duck skin gelatin was CIE L* 86.63, CIE a* -0.27 , and CIE $b^{*} 10.71$.

\section{Preparation of semi-dried restructured jerky}

Duck skin gelatin powder and phosphate were mixed in distilled water $(\mathrm{DW})$ at $60^{\circ} \mathrm{C}$ to obtain $0.5 \%$ and $1.0 \%$ gelatin solutions $(\mathrm{w} / \mathrm{w})$, which were cooled down until the central temperature reached $4{ }^{\circ} \mathrm{C}$.

Fresh pork ham was obtained from a local market (Jeonju, Korea) and ground $(\Phi-8 \mathrm{~mm})$. Table 1 showed the experimental design and formulation of the semi-dried restructured jerky. Each batch of samples comprised restructured jerkies with different levels of duck skin gelatin $(0 \%, 0.5 \%$, and $1.0 \%)$ with or without carrageenan $(0 \%$ and $0.3 \%)$. The ground lean meat and gelatin solution were homogenized in a Nr-963009 silent cutter (Hermann Scharfen GmbH \& Co., Witten, Germany) for $1 \mathrm{~min}$. Other ingredients such as sugar, salt, ascorbic acid, and carrageenan were added to the silent cutter and those were mixed for $2 \mathrm{~min}$. The homogenized meat jerky batter was stuffed into 
Table 1. Semi-dried restructured jerky formulations with duck skin gelatin and carrageenan

\begin{tabular}{|c|c|c|c|c|c|c|}
\hline Ingredients (\%) & $\begin{array}{c}\text { G0 } \\
\text { (Control) }\end{array}$ & GOC & G0.5 & G0.5C & G1 & G1C \\
\hline Ground lean meat & 100 & 100 & 100 & 100 & 100 & 100 \\
\hline Ice water & 10 & 10 & 10 & 10 & 10 & 10 \\
\hline Salt & 1.2 & 1.2 & 1.2 & 1.2 & 1.2 & 1.2 \\
\hline Phosphate & 0.20 & 0.20 & 0.20 & 0.20 & 0.20 & 0.20 \\
\hline Ascorbic acid & 0.03 & 0.03 & 0.03 & 0.03 & 0.03 & 0.03 \\
\hline Gelatin & - & - & 0.5 & 0.5 & 1.0 & 1.0 \\
\hline Carrageenan & - & 0.3 & - & 0.3 & - & 0.3 \\
\hline
\end{tabular}

G0, no added both duck skin gelatin and carrageenan; G0C, $0.3 \%$ carrageenan; $\mathrm{G} 0.5,0.5 \%$ duck skin gelatin; $\mathrm{G} 0.5 \mathrm{C}, 0.5 \%$ duck skin gelatin and $0.3 \%$ carrageenan; $\mathrm{G} 1,1.0 \%$ duck skin gelatin; G1C, $1.0 \%$ duck skin gelatin and $0.3 \%$ carrageenan.

$\Phi-20 \mathrm{~mm}$ size of cellulose casing (Viskase Sales, Chicago, IL, USA). Each preparation was cut into $20 \mathrm{~cm}$ long pieces. Then, the sample was dried at $55^{\circ} \mathrm{C}$ for $90 \mathrm{~min}$, followed by the removal of casing. Drying condition was at $55^{\circ} \mathrm{C}$ for $30 \mathrm{~min}, 65^{\circ} \mathrm{C}$ for $180 \mathrm{~min}$, and $80^{\circ} \mathrm{C}$ for $60 \mathrm{~min}$ (MAXi3501 chamber, Kerres, Postfach, Germany). This procedure was conducted in triplicates for each sample jerky.

\section{Proximate composition}

The moisture content (Drying oven method), protein content (Kjeldahl method), fat content (Soxhlet method), and ash content (Muffle furnace method) were measured using the standard method of AOAC [19].

\section{Water activity $\left(\mathrm{a}_{\mathrm{w}}\right)$}

Restructured jerky for water activity analysis was ground, and their water activity was measured in duplicates using a water activity meter (Novasina, Labmaster-aw, Lachen, Switzerland).

\section{Processing yield}

The processing yield was determined by Triyannanto and Lee [20] method. The change in the weight before and after the drying procedure was used to calculate the processing yield.

$\mathrm{pH}$

The semi-dried restructured jerky (5 g) was homogenized (8,000 rpm) with DW (20 mL). The pH of each homogenate was measured using a Mettler-Toledo $\mathrm{GmbH} \mathrm{pH}$ meter (Schwerzenbach, Switzerland).

\section{Color}

The CIE L* value, CIE $\mathrm{a}^{*}$ value, and $\mathrm{CIE} \mathrm{b}^{*}$ values of restructured jerky were determined using a CR-410 colorimeter (Minolta, Tokyo, Japan) calibrated using a white plate (Illuminate C observer $2^{\circ}$ ).

\section{Shear force}

Shear force value (test speed: $2 \mathrm{~mm} / \mathrm{s}$ ) was determined as described by De Huidobro et al. [21] using a TA-XT plus texture analyzer (Stable Micro Systems, Surrey, UK). The samples were cut into $2 \mathrm{~cm}$ (diameter) $\times 3 \mathrm{~cm}$ (height) pieces. 


\section{Rehydration capacity}

The rehydration experiments were carried out according to the method of Kim et al. [22] with suitable modifications. A $100 \mathrm{~mL}$ beaker was filled with semi-dried restructured jerky samples and DW.The weights of soaked samples were measured after 15,30, 45, and $60 \mathrm{~min}$.

\section{Scanning electron microscopy (SEM)}

Small pieces of semi-dried restructured jerky were used for SEM analysis. Each sample was fixed with $2 \mathrm{~mL}$ Karnovsky's fixative at $4^{\circ} \mathrm{C}$ for overnight and washed thrice with $0.05 \mathrm{M}$ sodium cacodylate buffer at room temperature for $10 \mathrm{~min}$ each. Samples were fixed with osmium tetroxide (2\%) in $0.1 \mathrm{M}$ sodium cacodylate buffer for $2 \mathrm{~h}$ at $4^{\circ} \mathrm{C}$ and washed with DW twice. Then, samples were dehydrated using gradually increasing ethyl alcohol concentrations for $10 \min (30 \%, 50 \%, 70 \%$, $80 \%, 90 \%$, and 99.8\%). Each samples was covered with aluminum stubs and coated with a layer of platinum under vacuum (E-1010, HITACHI, Tokyo, Japan). Micrographs of the semi-dried restructured jerky were obtained under a SEM (S-2380N, HITACHI, Tokyo, Japan).

\section{Sensory evaluation}

A sensory panel comprising 24 members from Korea Food Research Institute (KFRI) evaluated the sensory properties of restructured jerky samples. Panelists tasted the samples and cleansed their mouths with warm water. The following sensory items were evaluated using a 9-point descriptive scale (9, extremely desirable; 1 , extremely undesirable): appearance, flavor, texture, and overall acceptability.

\section{Statistical analysis}

All experimental data were analyzed using SPSS statistical software program (SPSS Ver. 20.0, IBM, Chicago, IL, USA). One-way analysis of variance was performed using the general linear model procedure (GLM) to investigate the addition effect of duck skin gelatin and carrageenan. Significance of differences among mean values was determined by Duncan's multiple range tests with the confidence level of $p<0.05$. Then, mean values and standard deviations were presented.

\section{RESULTS AND DISCUSSION}

\section{Proximate composition and water activity}

In Table 2, the proximate composition of semi-dried restructured jerky with duck skin gelatin and carrageenan is shown. Both duck skin gelatin and carrageenan had significant effect on moisture content of semi-dried restructured jerky $(p<0.001)$ (Table 5). The moisture content is the one of

Table 2. Proximate composition of semi-dried restructured jerky prepared with duck skin gelatin and carrageenan

\begin{tabular}{lcccccc}
\hline \multicolumn{1}{c}{ Traits } & $\begin{array}{c}\text { G0 } \\
\text { (Control) }\end{array}$ & G0C & G0.5 & G0.5C & G1 & G1C \\
\hline Moisture content (\%) & $40.99 \pm 0.12^{\mathrm{e}}$ & $41.32 \pm 0.16^{\mathrm{d}}$ & $42.46 \pm 0.13^{\mathrm{c}}$ & $43.54 \pm 0.15^{\mathrm{a}}$ & $43.09 \pm 0.02^{\mathrm{b}}$ & $43.63 \pm 0.08^{\mathrm{a}}$ \\
Protein content (\%) & $40.60 \pm 0.02^{\mathrm{a}}$ & $39.96 \pm 0.35^{\mathrm{ab}}$ & $39.90 \pm 0.23^{\mathrm{ab}}$ & $39.20 \pm 0.27^{\mathrm{b}}$ & $38.16 \pm 1.09^{\mathrm{c}}$ & $38.28 \pm 0.10^{\mathrm{c}}$ \\
Fat content (\%) & $9.11 \pm 0.07^{\mathrm{e}}$ & $8.95 \pm 0.14^{\mathrm{e}}$ & $10.41 \pm 0.08^{\mathrm{c}}$ & $9.75 \pm 0.11^{\mathrm{d}}$ & $10.95 \pm 0.15^{\mathrm{a}}$ & $10.66 \pm 0.13^{\mathrm{b}}$ \\
Ash content (\%) & $3.03 \pm 0.07^{\mathrm{d}}$ & $3.13 \pm 0.12^{\mathrm{cd}}$ & $3.11 \pm 0.12^{\mathrm{cd}}$ & $3.19 \pm 0.01^{\mathrm{bc}}$ & $3.00 \pm 0.22^{\mathrm{b}}$ & $3.03 \pm 0.20^{\mathrm{a}}$ \\
Water activity & $0.911 \pm 0.001^{\mathrm{ab}}$ & $0.910 \pm 0.003^{\mathrm{bc}}$ & $0.908 \pm 0.003^{\mathrm{c}}$ & $0.910 \pm 0.001^{\mathrm{bc}}$ & $0.914 \pm 0.002^{\mathrm{a}}$ & $0.913 \pm 0.001^{\mathrm{a}}$ \\
\hline
\end{tabular}

All values are mean \pm standard deviation of three replicates.

${ }^{\mathrm{a}-\mathrm{e}}$ Means within a row with different letters are significantly different.

G0, no added both duck skin gelatin and carrageenan; G0C, $0.3 \%$ carrageenan; G0.5, 0.5\% duck skin gelatin; G0.5C, $0.5 \%$ duck skin gelatin and $0.3 \%$ carrageenan; G1, $1.0 \%$ duck skin gelatin; G1C, $1.0 \%$ duck skin gelatin and $0.3 \%$ carrageenan. 
the factors which determine intermediate moisture food and the range of moisture content from $20 \%$ to $50 \%$ is known as a standard value of intermediate moisture food (IMF) [23-25]. The semidried restructured jerkies produced in this study had a moisture content of $40 \%$ to $44 \%$. Concerning the amount of gelatin added, G1 group had the highest $(p<0.05)$ moisture content, owing to the high water absorption property of gelatin [26]. Carrageenan is reported to exhibit a high water retention capability [27]. The jerkies containing carrageenan showed a higher moisture content compared to those without carrageenan $(p<0.05)$. The protein content of the G1 group was significantly $(p<0.05)$ lower than that of the control group (G0), even gelatin known a protein (Table 2). Table 5 also shows that duck skin gelatin has significant effect on protein content $(p<0.001)$. The decrease in the protein content following treatment may be associated with the fat content of duck skin gelatin. G0.5 and G1 groups showed high-fat content, while G1 groups showed high ash content compared to the control group (G0). The duck generally has abundant fat and ash contents in skin and these contents might be contained in the crude extracted gelatin even removed a separated fat [28]. Table 2 presents the difference in the water activity of semi-dried restructured jerky with duck skin gelatin and carrageenan. Water activity is related to the thermodynamic equilibrium state of jerky [2]. Jerky should have stable water activity value for avoiding its quality changes during storage [29]. In case of semi-dried jerky, the water activity was within the range of $0.88-0.91$ [30], and the jerkies from G0C, G0.5, and G0.5C groups satisfied this standard. The water activity of jerkies from G1 and G1C groups was the highest, while that of the jerkies from G0.5 group was the lowest $(p<0.05)$. According to Table 5, water activity of semi-dried restructured jerky was significantly affected by the addition of duck skin gelatin $(p<0.05)$, while not the addition of carrageenan. Similar observations were reported by Kim et al. [8] who found that the water activity of duck jerky decreased when the amount of konjac was increased while that of collagen decreased.

\section{$\mathrm{pH}$ and color}

Table 3 presents the $\mathrm{pH}$ and color of semi-dried restructured jerky prepared from duck skin gelatin and carrageenan. The $\mathrm{pH}$ values of semi-dried restructured jerky significantly $(p<0.05)$ increased with an increase in duck skin gelatin concentration and the addition of carrageenan. Both according to Kim et al. [17], the process of $\mathrm{pH}$ adjustment during gelatin neutralization affects the product. In the present study, the addition of duck skin gelatin neutralized to $\mathrm{pH} 7$ affected the $\mathrm{pH}$ of the semidried restructured jerky. When we measured the $\mathrm{pH}$ of $0.3 \%$ carrageenan in $\mathrm{DW}$, the value was 6.98 (data not shown). That $\mathrm{pH}$ might be affected by the $\mathrm{pH}$ of the semi-dried restructured jerky. The lightness and yellowness values of semi-dried restructured jerky significantly increased after the addition of duck skin gelatin and carrageenan, while the value of redness significantly decreased (Tables 3 and 5). Considering the amount of gelatin added, these results could be explained by color of duck skin gelatin. These observations are in line with those previously reported [31], wherein

Table 3. pH and color of semi-dried restructured jerky prepared with duck skin gelatin and carrageenan

\begin{tabular}{lccrrrr}
\hline \multicolumn{1}{c}{ Traits } & $\begin{array}{c}\text { G0 } \\
\text { (Control) }\end{array}$ & \multicolumn{1}{c}{ G0C } & G0.5 & G0.5C & G1 & G1C \\
\hline $\mathrm{pH}$ & $6.20 \pm 0.01^{\mathrm{d}}$ & $6.22 \pm 0.01^{\mathrm{bc}}$ & $6.21 \pm 0.01^{\mathrm{cd}}$ & $6.23 \pm 0.01^{\mathrm{b}}$ & $6.23 \pm 0.01^{\mathrm{b}}$ & $6.26 \pm 0.01^{\mathrm{a}}$ \\
$\mathrm{CIE} \mathrm{L}^{*}$ & $56.92 \pm 0.23^{\mathrm{c}}$ & $57.96 \pm 0.14^{\mathrm{b}}$ & $57.06 \pm 0.45^{\mathrm{c}}$ & $57.95 \pm 0.20^{\mathrm{b}}$ & $58.15 \pm 0.43^{\mathrm{b}}$ & $59.10 \pm 0.15^{\mathrm{a}}$ \\
$\mathrm{CIE} \mathrm{a}^{*}$ & $8.77 \pm 0.07^{\mathrm{a}}$ & $8.74 \pm 0.06^{\mathrm{a}}$ & $8.58 \pm 0.03^{\mathrm{b}}$ & $8.48 \pm 0.03^{\mathrm{c}}$ & $8.30 \pm 0.06^{\mathrm{d}}$ & $8.24 \pm 0.04^{\mathrm{d}}$ \\
$\mathrm{CIE} \mathrm{b}^{*}$ & $10.25 \pm 0.03^{\mathrm{d}}$ & $10.33 \pm 0.03^{\mathrm{d}}$ & $10.60 \pm 0.06^{\mathrm{c}}$ & $10.66 \pm 0.07^{\mathrm{c}}$ & $10.98 \pm 0.10^{\mathrm{b}}$ & $11.10 \pm 0.13^{\mathrm{a}}$ \\
\hline
\end{tabular}

All values are mean \pm standard deviation of three replicates.

${ }^{a-d}$ Means within a row with different letters are significantly different.

G0, no added both duck skin gelatin and carrageenan; G0C, $0.3 \%$ carrageenan; G0.5, 0.5\% duck skin gelatin; G0.5C, $0.5 \%$ duck skin gelatin and $0.3 \%$ carrageenan; G1, $1.0 \%$ duck skin gelatin; G1C, $1.0 \%$ duck skin gelatin and $0.3 \%$ carrageenan. 
surimi gel prepared with duck foot collagen showed a significant increase in all color parameters as compared to those prepared using dark flesh or white flesh fish. Similar results were also reported by Demirci et al. [32] who found that the lightness and yellowness of meatball increased with an increase in carrageenan levels.

\section{Processing yield and shear force}

Fig. 1 shows the processing yield of semi-dried restructured jerky with duck skin gelatin and carrageenan. No significant $(p>0.05)$ difference was observed in the processing yield according to the addition of duck skin gelatin. Schilling et al. [33] reported that the cooking loss for boneless cured ham manufactured with pork collagen was not different from that reported for the control ham. Prabhu et al. [34] noted no difference in cooking yield following the addition of $0.5 \%$ pork collagen. The G1C, G0.5C, and G0C respectively was higher $(p<0.05)$ processing yield compared to the same amount of gelatin. Table 5 also shows that the addition of carrageenan significantly affects the processing yield. These results are consistent with those of Trius et al. [35] that studied the interaction between carrageenan and meat proteins used in meat products. These authors reported that carrageenan helps in water retention of meat products by holding water in the interstitial spaces of protein gel. A similar trend was reported in the study by Candogan and Kolsarici [36], wherein low-fat beef frankfurters were made with pectin and carrageenan. These authors showed an increase in processing yield with the addition of carrageenan, owing to the improvement in the hydration and binding abilities of meat products.

Fig. 2 presents the effect of duck skin gelatin and carrageenan on the shear force values of semidried restructured jerky. Texture has an important role in the organoleptic property of jerky and affects the consumer preference [37]. Shear force is defined as the force that transforms the food shape [38] and correlates with muscle fiber, processing yield, and moisture content [29,39]. Duck skin gelatin and carrageenan had significant effects on shear force of semi-dried restructured jerky, respectively $(p<0.001$, Table 5). In Fig. 2, the shear force values of semi-dried restructured jerky with duck skin gelatin and carrageenan was lower $(p<0.05)$ than that of the control (G0), and the lowest $(p<0.05)$ shear force was observed for the semi-dried restructured jerkies from $\mathrm{G} 0.5 \mathrm{C}$ and G1C groups (Fig. 2). Kim et al. [29] found that the increase in the addition of chicken feet gelatin to semi-dried chicken jerky resulted in a decrease in shear force. Similar results were also reported

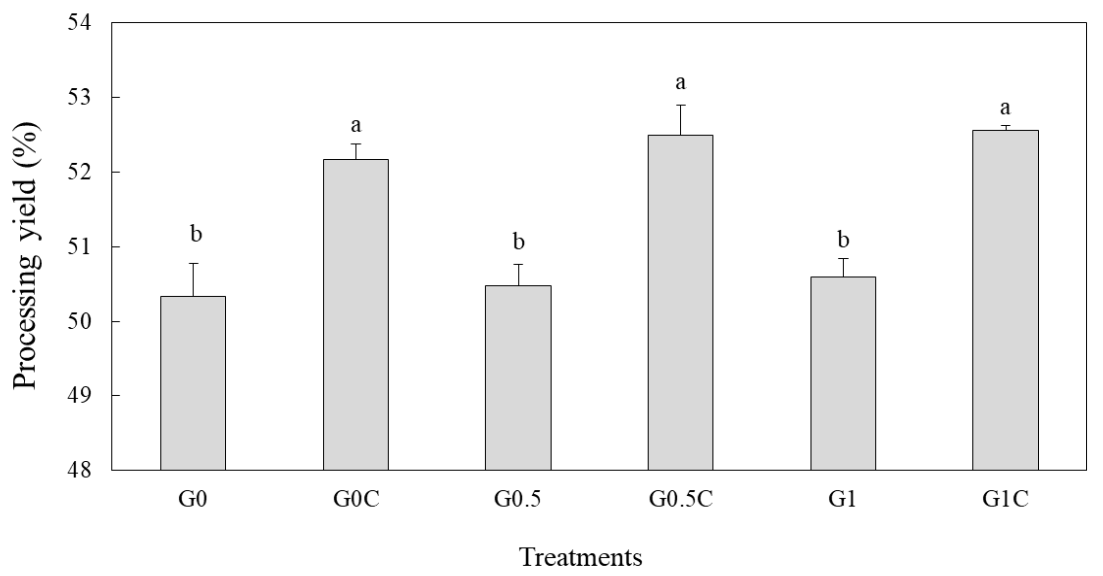

Fig. 1. Processing yield of semi-dried restructured jerky prepared with duck skin gelatin and carrageenan. ${ }^{\mathrm{a}, \mathrm{b}}$ Different letters on the top of the column meant significantly different. $\mathrm{G} 0$, no added both duck skin gelatin and carrageenan; G0C, $0.3 \%$ carrageenan; G0.5, 0.5\% duck skin gelatin; G0.5C, $0.5 \%$ duck skin gelatin and $0.3 \%$ carrageenan; $\mathrm{G} 1,1.0 \%$ duck skin gelatin; $\mathrm{G} 1 \mathrm{C}, 1.0 \%$ duck skin gelatin and $0.3 \%$ carrageenan. 


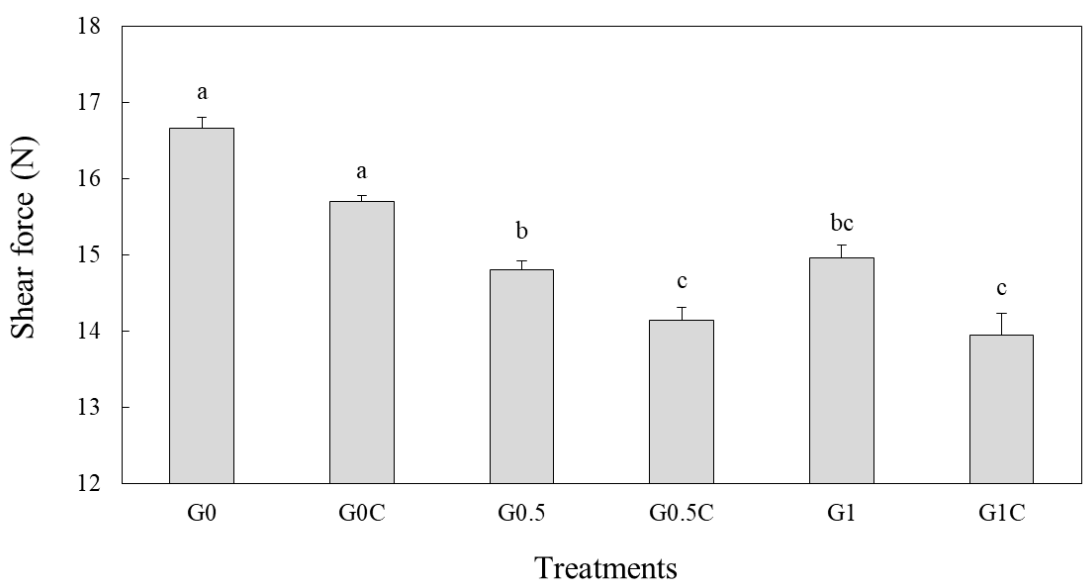

Fig. 2. Shear force of semi-dried restructured jerky prepared with duck skin gelatin and carrageenan. ${ }^{a-d}$ Different letters on the top of the column meant significantly different. G0, no added both duck skin gelatin and carrageenan; G0C, $0.3 \%$ carrageenan; G0.5, 0.5\% duck skin gelatin; G0.5C, $0.5 \%$ duck skin gelatin and $0.3 \%$ carrageenan; $\mathrm{G} 1,1.0 \%$ duck skin gelatin; $\mathrm{G} 1 \mathrm{C}, 1.0 \%$ duck skin gelatin and $0.3 \%$ carrageenan.

by Kim et al. [8] who showed that the shear force values of duck jerky made with the collagen and konjac were lower than that of duck jerky made with only collagen. These authors convinced that the reduced shear force values owing to both collagen and konjac addition positively improved the tenderness of jerky. Thus, the addition of duck skin gelatin and carrageenan to semi-dried restructured jerky improved its processing yield and tenderness.

\section{Rehydration capacity}

The effect of duck skin gelatin and carrageenan on the rehydration capacity of semi-dried restructured jerky is presented in Fig. 3. Rehydration capacity indicates hysteresis during rehydration owing to cellular and structural disturbances while drying [8]. Therefore, it is one of the most important factors affect the sensory properties such as tenderness during mastication [6]. G1C, G0.5C,

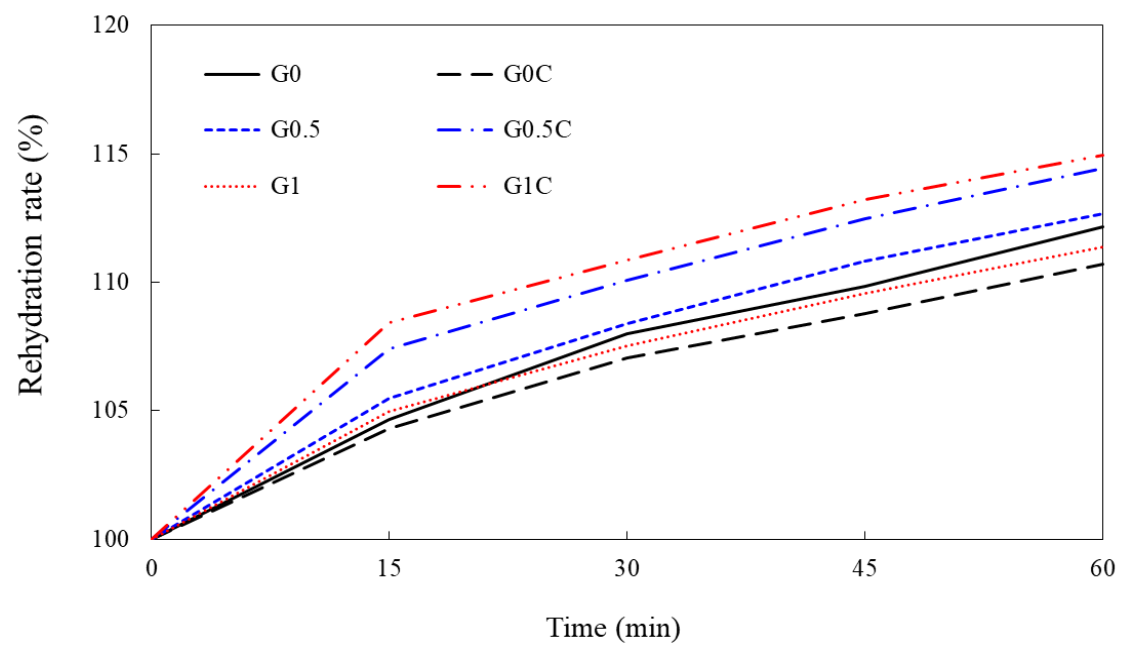

Fig. 3. Rehydration capacity of semi-dried restructured jerky prepared with duck skin gelatin and carrageenan. G0, no added both duck skin gelatin and carrageenan; G0C, $0.3 \%$ carrageenan; G0.5, 0.5\% duck skin gelatin; $\mathrm{G} 0.5 \mathrm{C}, 0.5 \%$ duck skin gelatin and $0.3 \%$ carrageenan; $\mathrm{G} 1,1.0 \%$ duck skin gelatin; $\mathrm{G} 1 \mathrm{C}, 1.0 \%$ duck skin gelatin and $0.3 \%$ carrageenan. 
and G0.5 groups showed higher rehydration capacity than the control (G0) group $(p<0.05)$. Some researchers have reported no effect of $1 \%$ gelatin on the rehydration capacity of jerky [6,29]. Our results are in agreement with those of Kim et al. [8] who observed that the rehydration capacity of duck jerky made with a composite of konjac and collagen (40/60 and 60/40) was higher compared to that of the jerky treated with either konjac or collagen.

\section{Scanning electron microscopy (SEM)}

SEM images of semi-dried restructured jerky prepared from duck skin gelatin and carrageenan are shown in Fig. 4. When gelatin was added in the jerky, a spherical gel-type structure was identified and which was not shown in G0. Additionally, the size of the gel-type structure increases when carrageenan was added with gelatin. The gel-type structure of G1C showed the largest size and
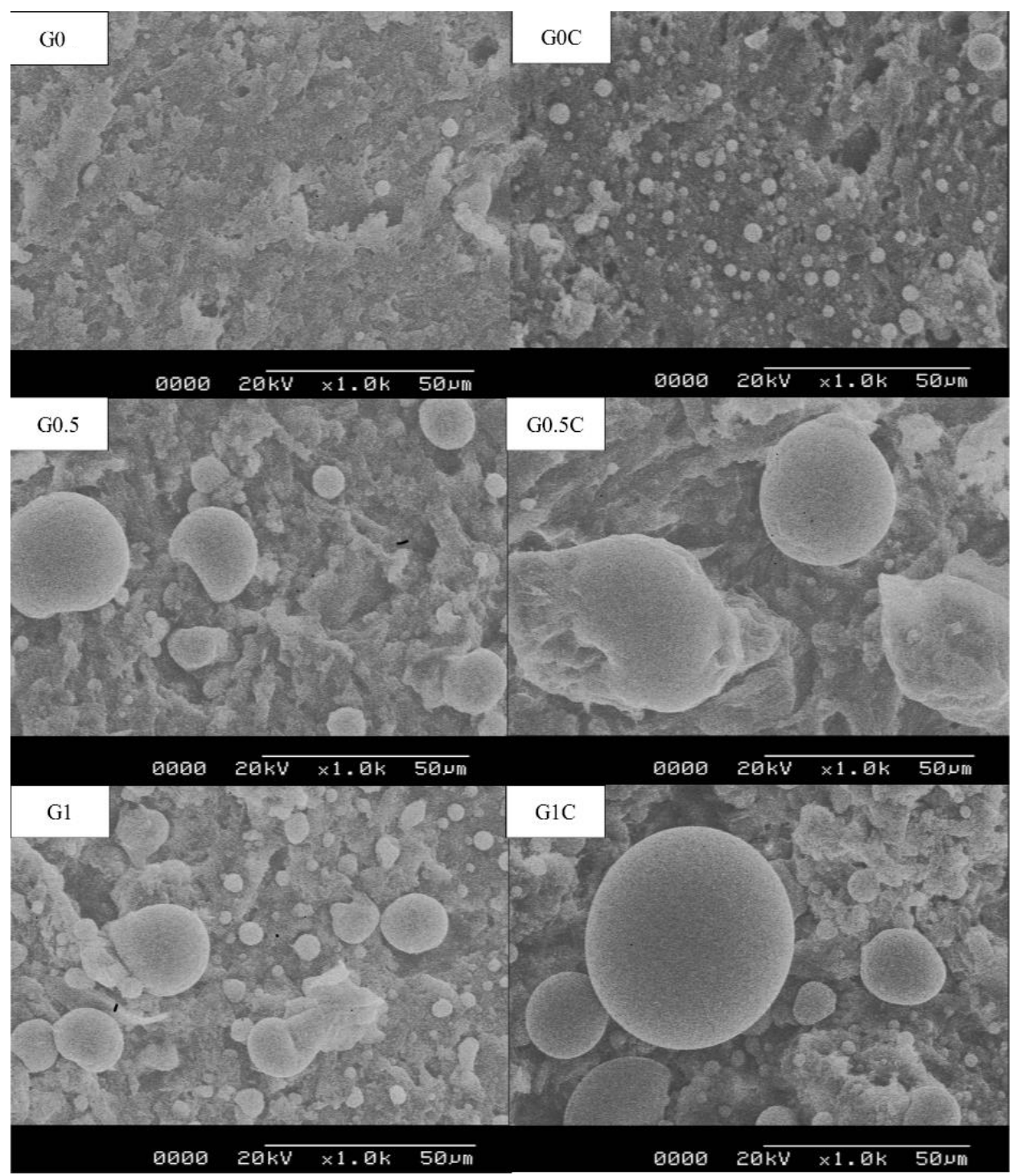

Fig. 4. Scanning electron microscopy of semi-dried restructured jerky prepared with duck skin gelatin and carrageenan. G0, no added both duck skin gelatin and carrageenan; G0C, $0.3 \%$ carrageenan; G0.5, 0.5\% duck skin gelatin; $\mathrm{G} 0.5 \mathrm{C}, 0.5 \%$ duck skin gelatin and $0.3 \%$ carrageenan; $\mathrm{G} 1,1.0 \%$ duck skin gelatin; $\mathrm{G} 1 \mathrm{C}, 1.0 \%$ duck skin gelatin and $0.3 \%$ carrageenan. 
the smallest number. Andrès et al. [40] reported gel-type structures in the micrograph of chicken sausage treated with whey protein and guar gum. These authors suggested that gel-type structures improved the texture properties such as cohesiveness. Similar results were reported by Eyiler Yilmaz et al. [41] who found gel structures in the micrograph of low-fat frankfurter containing kappa-carrageenan. The authors suggested that these structures were related to hardness because low-fat frankfurter treated with kappa-carrageenan had lower hardness than those from the control group.

\section{Sensory evaluation}

The effect of duck skin gelatin and carrageenan of on the sensory properties of semi-dried restructured jerky is presented in Table 4 . In sensory values, the appearance score of semi-dried restructured jerky was unaffected by the addition of duck skin gelatin. Meanwhile, the addition of gelatin affects the flavor, texture, and overall acceptability $(p<0.001)$, and the addition of carrageenan affects appearance, flavor, and texture $(p<0.05$, Table 5). The flavor, texture, and overall acceptability

Table 4. Sensory evaluation of semi-dried restructured jerky prepared with duck skin gelatin and carrageenan

\begin{tabular}{lcccccc}
\hline \multicolumn{1}{c}{ Traits } & $\begin{array}{c}\text { G0 } \\
\text { (Control) }\end{array}$ & G0C & G0.5 & G0.5C & G1 & G1C \\
\hline Appearance ${ }^{1)}$ & $7.75 \pm 0.85$ & $7.38 \pm 0.71$ & $7.25 \pm 0.68$ & $7.25 \pm 0.85$ & $7.75 \pm 0.85$ & $7.00 \pm 0.51$ \\
Flavor & $5.13 \pm 1.08^{\mathrm{c}}$ & $5.63 \pm 1.35^{\mathrm{bc}}$ & $5.75 \pm 0.99^{\mathrm{bc}}$ & $6.00 \pm 1.77^{\mathrm{b}}$ & $6.13 \pm 1.57^{\mathrm{b}}$ & $7.00 \pm 1.14^{\mathrm{a}}$ \\
Texture & $4.88 \pm 0.80^{\mathrm{c}}$ & $5.50 \pm 1.62^{\mathrm{c}}$ & $6.50 \pm 1.25^{\mathrm{b}}$ & $6.50 \pm 1.62^{\mathrm{b}}$ & $6.75 \pm 1.42^{\mathrm{ab}}$ & $7.50 \pm 1.02^{\mathrm{a}}$ \\
Overall acceptability & $4.88 \pm 0.95^{\mathrm{d}}$ & $5.38 \pm 1.61^{\mathrm{cd}}$ & $6.13 \pm 1.19^{\mathrm{bc}}$ & $6.13 \pm 1.80^{\mathrm{bc}}$ & $6.75 \pm 1.11^{\mathrm{ab}}$ & $7.38 \pm 1.13^{\mathrm{a}}$ \\
\hline
\end{tabular}

All values are mean \pm standard deviation of three replicates.

${ }^{1)}$ Appearance, flavor, overall acceptability (1, extremely undesirable; 9 , extremely desirable), texture (1, extremely tough; 9 , extremely tender) were expressed for evaluating sensory attributes.

${ }^{a-d}$ Means within a row with different letters are significantly different.

G0, no added both duck skin gelatin and carrageenan; G0C, $0.3 \%$ carrageenan; G0.5, $0.5 \%$ duck skin gelatin; G0.5C, $0.5 \%$ duck skin gelatin and $0.3 \%$ carrageenan; G1, $1.0 \%$ duck skin gelatin; G1C, $1.0 \%$ duck skin gelatin and $0.3 \%$ carrageenan.

Table 5. Significance of main effects (duck skin gelatin and carrageenan) and their interactions on quality characteristics of semi-dried restructured jerky

\begin{tabular}{|c|c|c|c|}
\hline Traits & Duck skin gelatin & Carrageenan & $\begin{array}{l}\text { Interaction between duck skin gelatin } \\
\text { and carrageenan }\end{array}$ \\
\hline Moisture content & $* \star \star$ & $* * \star$ & $* * \star$ \\
\hline Protein content & $\star \star \star *$ & NS & NS \\
\hline Fat content & $\star * \star$ & $\star * *$ & * \\
\hline Ash content & ** & * & NS \\
\hline Water acivity & * & NS & * \\
\hline Processing yield & NS & $* * *$ & NS \\
\hline $\mathrm{pH}$ & $* * *$ & $\star \star \star *$ & * \\
\hline $\mathrm{CIE} \mathrm{L*}$ & $* * *$ & $* * *$ & NS \\
\hline $\mathrm{CIE} a^{*}$ & $\star * *$ & * & NS \\
\hline $\mathrm{CIE} \mathrm{b*}$ & ** & * & NS \\
\hline Shear force & $* \star *$ & $* * *$ & NS \\
\hline Apprearance & NS & $* *$ & NS \\
\hline Flavor & $* * *$ & * & NS \\
\hline Texture & 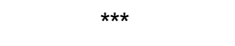 & * & NS \\
\hline Overall acceptability & $* * *$ & NS & NS \\
\hline
\end{tabular}

$p<0.05, " p<0.01, " m p<0.001$.

NS, no significance. 
scores were the highest $(p<0.05)$ for the G1C group (Table 4). Several researchers reported that the texture property of jerky is the most important sensory attribute [2,8,17, 29]. Kim et al. [29] found that semi-dried jerky showed an increase in tenderness score with an increase in the addition of chicken feet gelatin. These results are agreed with those of the study by Demirci et al. [32], that the hardness of meatballs treated with $0.5 \%$ carrageenan was lower than that of control meatballs. Therefore, the semi-dried restructured jerky prepared with duck skin gelatin and carrageenan in our study showed improved sensory properties.

\section{CONCLUSION}

We evaluated the effect of duck skin gelatin and carrageenan on the quality of semi-dried restructured jerky. As a result, the processing yield and rehydration capacity of jerkies from $\mathrm{G} 0.5 \mathrm{C}$ and $\mathrm{G} 1 \mathrm{C}$ groups were higher than those reported for jerkies from other treatment groups. The shear force was the lowest for G0.5C and G1C groups, while overall acceptability scores of G1C were the highest. The results of this study demonstrated that the addition of $1.0 \%$ duck skin gelatin and $0.3 \%$ carrageenan to restructured jerky formulations may result in optimized quality characteristics.

\section{REFERENCES}

1. Ha J, Lee J, Lee S, Kim S, Choi Y, Oh H, et al. Mathematical models to describe the kinetic behavior of Staphylococcus aureus in jerky. Food Sci Anim Resour. 2019;39:371-7.

2. Choi JH, Jeong JY, Han DJ, Choi YS, Kim HY, Lee MA, et al. Effects of pork/beef levels and various casings on quality properties of semi-dried jerky. Meat Sci. 2008;80:278-86.

3. Han DJ, Jeong JY, Choi JH, Choi YS, Kim HY, Lee MA, et al. Effects of drying conditions on quality properties of pork jerky. Korean J Food Sci Anim Resour. 2007;27:29-34.

4. Ku SK, Park JD, Lee NH, Kim HJ, Kim YB. Physicochemical and sensory properties of restructured jerky with four additives. Korean J Food Sci Anim Resour. 2013;33:572-80.

5. Oh JS, Han IJ, Park JG, Park JN, Song BS, Kim JH, et al. Effect of gamma irradiation on physicochemical and sensory properties of restructured pork jerky.J Korean Soc Food Sci Nutr. 2008;37:362-6.

6. Song DH, Choi JH, Choi YS, Kim HW, Hwang KE, Kim YJ, et al. Effects of mechanically deboned chicken meat (MDCM) and collagen on the quality characteristics of semi-dried chicken jerky. Korean J Food Sci Anim Resour. 2014;34:727-35.

7. An KII, Choi JH, Choi YS, Han DJ, Kim HY, Lee MA, et al. Effects of kimchi powder on quality characteristics of semi-dried pork jerky. Korean J Food Sci Anim Resour. 2010;30:198205.

8. Kim TK, Kim HW, Lee YY, Jang HW, Kim YB, Choi YS. Quality characteristics of duck jerky: combined effects of collagen and konjac. Poult Sci. 2020;99:629-36.

9. Ayadi MA, Kechaou A, Makni I, Attia H. Influence of carrageenan addition on turkey meat sausages properties.J Food Eng. 2009;93:278-83.

10. Necas J, Bartosikova L. Carrageenan: a review. Vet Med (Praha). 2013;58:187-205.

11. Pietrasik Z. Binding and textural properties of beef gels processed with $\kappa$-carrageenan, egg albumin and microbial transglutaminase. Meat Sci. 2003;63:317-24.

12. DeFreitas Z, Sebranek JG, Olson DG, Carr JM. Carrageenan effects on salt-soluble meat proteins in model systems.J Food Sci. 1997;62:539-43.

13. Pietrasik Z, Li-Chan ECY. Binding and textural properties of beef gels as affected by protein, $\kappa$-carrageenan and microbial transglutaminase addition. Food Res Int. 2002;35:91-8. 
14. Yeo EJ, Kim HW, Hwang KE, Song DH, Kim YJ, Ham YK, et al. Effect of duck feet gelatin on physicochemical, textural, and sensory properties of low-fat frankfurters. Korean J Food Sci Anim Resour. 2014;34:415-22.

15. Lee $\mathrm{CH}$, Chin $\mathrm{KB}$. Evaluation of pork myofibrillar protein gel with pork skin gelatin on rheological properties at different salt concentrations. Food Sci Anim Resour. 2019;39:576-84.

16. Rafieian F, Keramat J, Kadivar M. Optimization of gelatin extraction from chicken deboner residue using RSM method.J Food Sci Technol. 2013;50:374-80.

17. Kim HY, Lee JW, Kim JH, Kim GW. Effects of chicken feet gelatin on physicochemical and sensory properties of restructured chicken jerky. Korean J Poult Sci. 2015;42:327-33.

18. Kim TK, Ham YK, Shin DM, Kim HW, Jang HW, Kim YB, et al. Extraction of crude gelatin from duck skin: effects of heating methods on gelatin yield. Poult Sci. 2020;99:590-6.

19. AOAC [Association of Official Analytical Chemists] International. Official methods of analysis of AOAC International. 17th ed. Gaithersburg, MD: AOAC International; 2000.

20. Triyannanto E, Lee KT. Evaluation of honey and rice syrup as replacements for sorbitol in the production of restructured duck jerky. Asian-Australas J Anim Sci. 2016;29:271-9.

21. Ruiz de Huidobro F, Miguel E, Blázquez B, Onega E. A comparison between two methods (Warner-Bratzler and texture profile analysis) for testing either raw meat or cooked meat. Meat Sci. 2005;69:527-36.

22. Kim JM, Choi JH, Han DJ, Choi YS, Jeong JY, Choi GH, et al. Effect of protease produced from Bacillus polyfermenticus SCD on quality of jerky. Food Sci Biotechnol. 2008;17:389-95.

23. Labuza T, Tannenbaum SR, Karel M. Water content and stability of low moisture and intermediate moisture foods. Food Technol. 1970;24:543-50.

24. Nopwinyuwong A, Trevanich S, Suppakul P. Development of a novel colorimetric indicator label for monitoring freshness of intermediate-moisture dessert spoilage. Talanta. 2010;81:112632.

25. Qiu L, Zhang M, Tang J, Adhikari B, Cao P. Innovative technologies for producing and preserving intermediate moisture foods: a review. Food Res Int. 2019;116:90-102.

26. Gómez-Guillén MC, Giménez B, López-Caballero ME, Montero MP. Functional and bioactive properties of collagen and gelatin from alternative sources: a review. Food Hydrocoll. 2011;25:1813-27.

27. Kim TK, Shim JY, Hwang KE, Kim YB, Sung JM, Paik HD, et al. Effect of hydrocolloids on the quality of restructured hams with duck skin. Poult Sci. 2018;97:4442-9.

28. Kim DH, Kim TK, Kim YB, Sung JM, Jang YJ, Shim JY, et al. Effect of the duck skin on quality characteristics of duck hams. Korean J Food Sci Anim Resour. 2017;37:360-7.

29. Kim HY, Kim KJ, Lee JW, Kim GW, Kim CJ. Effects of chicken feet gelatin and wheat fiber levels on quality properties of semi-dried chicken jerky. Korean J Food Sci Anim Resour. 2012;32:732-9.

30. Ismail I, Fauzi NHM, Baki MZ, Hoon HL. Effects of different drying methods and hydrocolloids on quality properties of semi-dried catfish jerky. Malaysian J Appl Sci. 2017;2:11-8.

31. Huda N, Seow EK, Normawati MN, Nik Aisyah NM, Fazilah A, Easa AM. Effect of duck feet collagen addition on physicochemical properties of surimi. Int Food Res J. 2013;20:53744.

32. Demirci ZO, Yılmaz I, Demirci AŞ. Effects of xanthan, guar, carrageenan and locust bean gum addition on physical, chemical and sensory properties of meatballs. J Food Sci Technol. 2014;51:936-42.

33. Schilling MW, Mink LE, Gochenour PS, Marriott NG, Alvarado CZ. Utilization of pork collagen for functionality improvement of boneless cured ham manufactured from pale, soft, and 
exudative pork. Meat Sci. 2003;65:547-53.

34. Prabhu GA, Doerscher DR, Hull DH. Utilization of pork collagen protein in emulsified and whole muscle meat products. J Food Sci. 2004;69:C388-92.

35. Trius A, Sebranek JG, Lanier T. Carrageenans and their use in meat products. Crit Rev Food Sci Nutr. 1996;36:69-85.

36. Candogan K, Kolsarici N. The effects of carrageenan and pectin on some quality characteristics of low-fat beef frankfurters. Meat Sci. 2003;64:199-206.

37. Konieczny P, Stangierski J, Kijowski J. Physical and chemical characteristics and acceptability of home style beef jerky. Meat Sci. 2007;76:253-7.

38. Kim TH, Choi YS, Choi JH, Han DJ, Kim HY, Lee MA, et al. Physicochemical properties and sensory characteristics of semi-dried pork jerky with rice bran fiber. Korean J Food Sci Anim Resour. 2010;30:966-74.

39. Yang HS, Hwang YH, Joo ST, Park GB. The physicochemical and microbiological characteristics of pork jerky in comparison to beef jerky. Meat Sci. 2009;82:289-94.

40. Andrès S, Zaritzky N, Califano A. The effect of whey protein concentrates and hydrocolloids on the texture and colour characteristics of chicken sausages. Int J Food Sci Technol. 2006;41:954-61.

41. Eyiler Yilmaz E, Vural H, Jafarzadeh Yadigari R. Thermal, microscopic, and quality properties of low-fat frankfurters and emulsions produced by addition of different hydrocolloids. Int J Food Prop. 2017;20:1987-2002. 